ISSN 2073-4344

www.mdpi.com/journal/catalysts

Article

\title{
Phosphorus and Nitrogen Dual Doped and Simultaneously Reduced Graphene Oxide with High Surface Area as Efficient Metal-Free Electrocatalyst for Oxygen Reduction
}

\author{
Xiaochang Qiao, Shijun Liao *, Chenghang You and Rong Chen \\ The Key Laboratory of Fuel Cell Technology of Guangdong Province, School of Chemistry and \\ Chemical Engineering, South China University of Technology, Guangzhou 510641, China; \\ E-Mails: qxc19861002@163.com (X.Q.); youchh@163.com (C.Y.); c.r10@mail.scut.edu.cn (R.C.) \\ * Author to whom correspondence should be addressed; E-Mail: chsjliao@scut.edu.cn; \\ Tel./Fax: +86-20-8711-3586.
}

Academic Editor: Minhua Shao

Received: 13 May 2015 / Accepted: 15 June 2015 / Published: 23 June 2015

\begin{abstract}
A P, N dual doped reduced graphene oxide (PN-rGO) catalyst with high surface area $\left(376.20 \mathrm{~m}^{2} \cdot \mathrm{g}^{-1}\right)$, relatively high P-doping level $(1.02$ at. \%) and a trace amount of $\mathrm{N}(0.35$ at. \%) was successfully prepared using a one-step method by directly pyrolyzing a homogenous mixture of graphite oxide (GO) and diammonium hydrogen phosphate $\left(\left(\mathrm{NH}_{4}\right)_{2} \mathrm{HPO}_{4}\right)$ in an argon atmosphere, during which the thermal expansion, deoxidization of GO and $\mathrm{P}, \mathrm{N}$ co-doping were realized simultaneously. The catalyst exhibited enhanced catalytic performances for oxygen reduction reaction (ORR) via a dominated four-electron reduction pathway, as well as superior long-term stability, better tolerance to methanol crossover than that of commercial $\mathrm{Pt} / \mathrm{C}$ catalyst in an alkaline solution.
\end{abstract}

Keywords: phosphorus and nitrogen dual doped; graphene; carbon catalyst; fuel cell; oxygen reduction reaction

\section{Introduction}

A crucial component of a fuel cell is the electrocatalyst for the cathodic oxygen reduction reaction (ORR) [1]. Pt-based precious metals are regarded as the most effective ORR electrocatalysts developed to date. However, they suffer from a number of drawbacks including the scarcity and 
consequent high cost of $\mathrm{Pt}$, as well as their poor durability and low tolerance to methanol crossover [2]. Accordingly, considerable effort has been devoted to developing nonprecious-metal [3-10] and metal-free [11-14] ORR catalysts. Among such candidates, carbon materials doped with heteroatoms have attracted a great deal of attention due to their relative cost-effectiveness, good long-term durability, and excellent tolerance to methanol crossover.

Graphene, a two-dimensional monolayer of $\mathrm{sp}^{2}$-hybridized carbon atoms packed in a honeycomb lattice, has recently become an attractive candidate, due to its superior electrical conductivity, high surface area and excellent mechanical properties. Both theoretical calculations and experimental studies reveal that incorporating foreign atoms into the graphene structure can effectively tailor the material's electronic and chemical properties [15-17]. Recently, graphene doped with heteroatoms such as nitrogen, sulfur, boron, and iodine has yielded metal-free ORR electrocatalysts with enhanced electrochemical performance [13,18-22]. This performance boost is attributed to the heteroatoms, because their electronegativity (N: 3.04; S: 2.58; B: 2.04; I: 2.66) differs from that of carbon (2.55), they break carbon's electroneutrality, creating charged sites and consequently favoring $\mathrm{O}_{2}$ adsorption during the ORR process. Since phosphorus has a lower electronegativity (2.19) than carbon, it is well worth exploring the unique properties of P-doped graphene. Liu et al. prepared P-doped graphene by pyrolyzing graphene oxide with 1-butyl-3-methlylimidazolium hexafluorophosphate, and achieved, in an alkaline solution, an ORR catalytic performance comparable to that of commercial $\mathrm{Pt} / \mathrm{C}$ [23]. Zhang et al. synthesized P-doped graphene by thermally annealing a mixture of graphite oxide (GO) and triphenylphosphine (TPP), and the resultant catalyst showed remarkable catalytic activity toward the ORR [24]. However, while exciting results have been obtained with P-doped graphene, just a few investigations into this type of catalyst have been reported to date. Furthermore, it has been reported that the co-doping of $\mathrm{P}$ and $\mathrm{N}$ can further improve the carbon materials' ORR catalytic activity, due to the synergistic effect [25].

Herein, we propose a one-step method for preparing a $\mathrm{P}, \mathrm{N}$ dual-doped reduced graphene oxide (PN-rGO) catalyst, using diammonium hydrogen phosphate $\left(\left(\mathrm{NH}_{4}\right)_{2} \mathrm{HPO}_{4}\right)$ as both phosphorus and nitrogen sources. In an alkaline medium, the as-prepared PN-rGO exhibited enhanced ORR electrocatalytic activity, good long-term stability, high tolerance to methanol crossover, and high selectivity for the four-electron reduction pathway.

\section{Results and Discussion}

Figure 1 shows typical SEM and TEM images of the PN-rGO catalyst. As can be seen in Figure 1a,b ultrathin, crumpled PN-rGO nanosheets are randomly arranged and overlapped with each other, these could easily have formed a slit-shaped porous structure, and indeed, such a structure was confirmed by Brunauer-Emmett-Teller (BET) testing (Figure 3). In Figure 1c, the PN-rGO nanosheets are transparent and wrinkled, like wavy silk veils. The high-resolution TEM image (Figure 1d) shows well-defined graphitic lattice fringes, indicating the good crystallization of the PN-rGO nanosheets. Actually, the morphology of our product is quite consistent with those reported previously $[18,19]$.

Figure 2a shows the X-ray diffraction (XRD) patterns of GO, rGO and PN-rGO. GO exhibited a peak at $2 \theta=11^{\circ}$ with an interlayer distance of $0.8 \mathrm{~nm}$, which is larger than the interlayer distance of graphite $(0.34 \mathrm{~nm})$, revealing that many different oxygen-containing groups were intercalated within 
the interlayer space. The peak at $11^{\circ}$ completely disappeared after annealing, replaced by a broad peak at $2 \theta=22^{\circ}$ for $\mathrm{rGO}$ and PN-rGO, with a d-spacing of $0.4 \mathrm{~nm}$, implying that the successful reduction of $\mathrm{GO}$ to reduced graphene oxide.

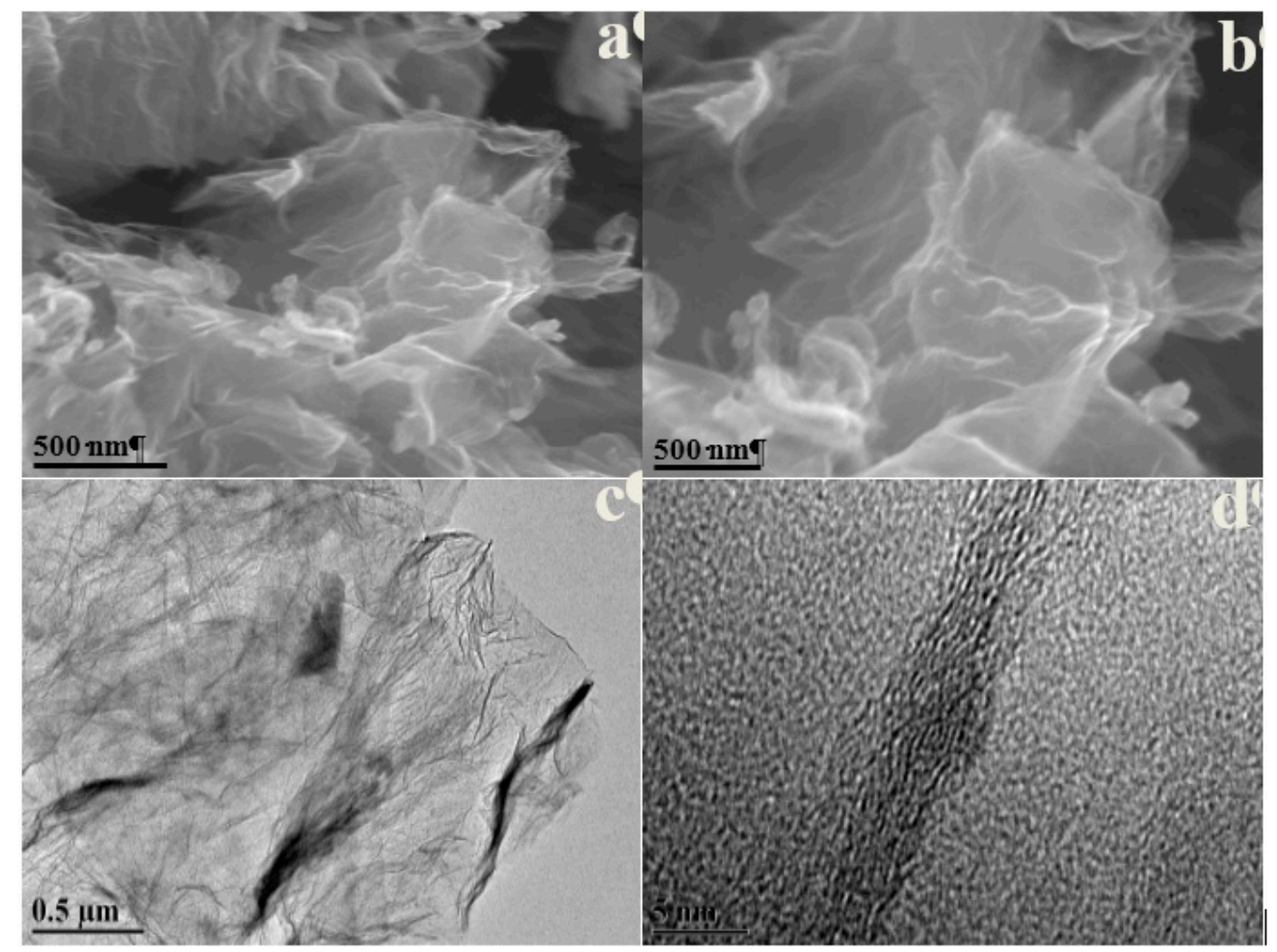

Figure 1. Scanning electron microscopy (SEM) images $(\mathbf{a}, \mathbf{b})$ and transmission electron microscopy (TEM) images (c, d) of $\mathrm{P}, \mathrm{N}$ dual doped reduced graphene oxide (PN-rGO).
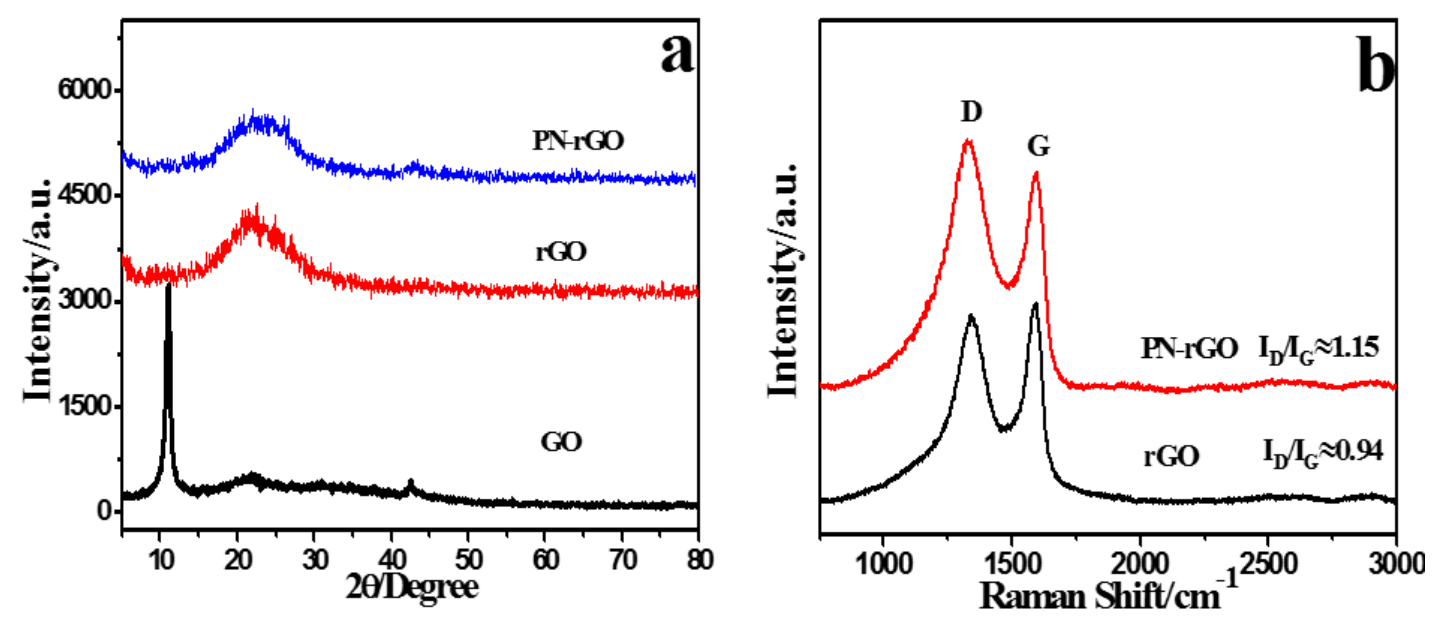

Figure 2. X-ray diffraction (XRD) patterns of GO, rGO and PN-rGO (a), Raman spectra of rGO and PN-rGO (b).

Further structural information about PN-rGO was obtained from Raman spectroscopy. As shown in Figure $2 \mathrm{~b}$, similar to all $\mathrm{sp}^{2}$-carbons, two distinct peaks appeared near $1350 \mathrm{~cm}^{-1}$ and $1580 \mathrm{~cm}^{-1}$, corresponding to the $\mathrm{D}$ band and $\mathrm{G}$ band, respectively. The $\mathrm{D}$ band is resulting from the disordered carbon atoms, whereas the $\mathrm{G}$ band from $\mathrm{sp}^{2}$-hybridized graphitic carbon atoms. The intensity ratio of 
$I_{\mathrm{D}} / I_{\mathrm{G}}$ generally provides a gauge for the lever of disorder. Evidently, the $I_{\mathrm{D}} / I_{\mathrm{G}}$ value of $\mathrm{PN}-\mathrm{rGO}(1.15)$ was relatively higher than that of $\mathrm{rGO}(0.94)$ due to the incorporated phosphorus atoms.

The $\mathrm{N}_{2}$ adsorption-desorption isotherms and the corresponding pore size distribution curves of PN-rGO and rGO are shown in Figure 3. According to the International Union of Pure and Applied Chemistry classification, the $\mathrm{N}_{2}$ adsorption-desorption isotherms of the two samples were type IV, with hysteresis loops type $\mathrm{H}_{3}$. A type IV adsorption-desorption isotherm indicates the presence of mesopores, while a type $\mathrm{H}_{3}$ hysteresis loop of is correlated with slit-shaped pores, possibly between parallel layers. This result is consistent with the SEM observations. Surface area and pore volume for PN-rGO were $376.2 \mathrm{~m}^{2} \cdot \mathrm{g}^{-1}$ and $1.50 \mathrm{~cm}^{3} \cdot \mathrm{g}^{-1}$, and for $\mathrm{rGO} 260.2 \mathrm{~m}^{2} \cdot \mathrm{g}^{-1}$ and $1.17 \mathrm{~cm}^{3} \cdot \mathrm{g}^{-1}$, respectively. The greatly increased BET surface area and pore volume of PN-rGO may have been due to the activation effect of $\left(\mathrm{NH}_{4}\right)_{2} \mathrm{HPO}_{4}$ on carbon [26,27]. The high surface area and large pore volume of PN-rGO could have (i) exposed more active sites and (ii) favored the mass transport of reactants and products.
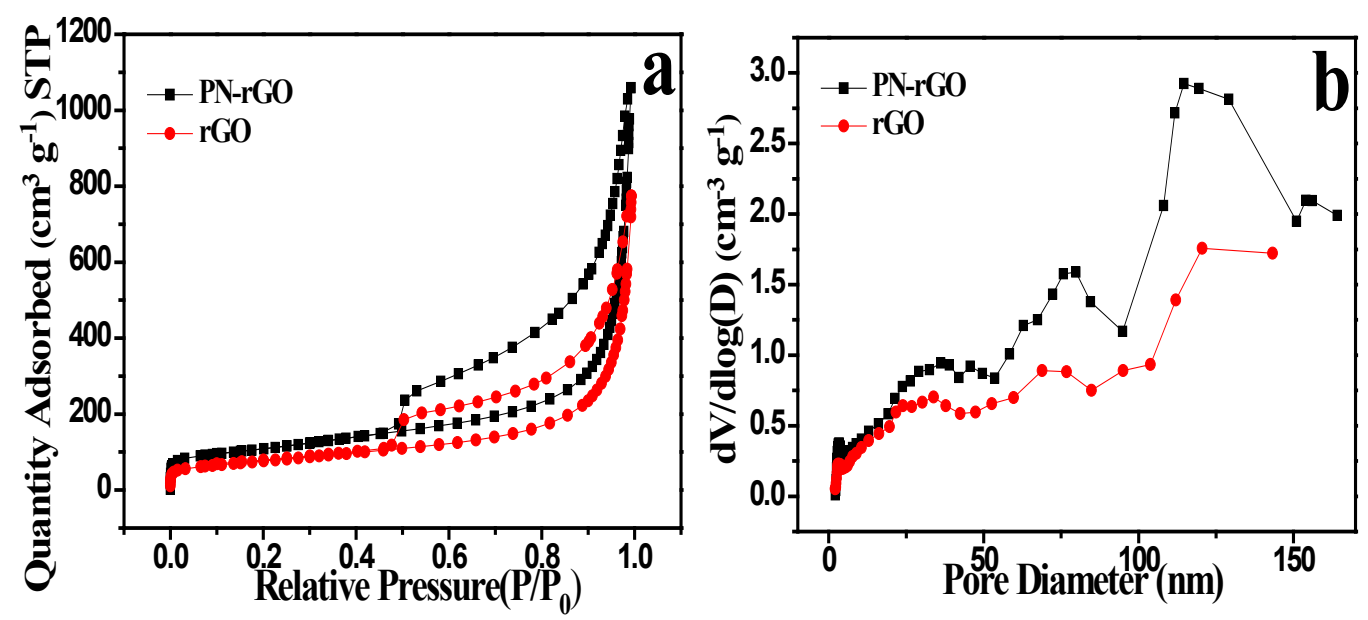

Figure 3. Nitrogen adsorption-desorption isotherms (a) and the corresponding pore size distribution curve of PN-rGO and rGO (b).

To further investigate the elemental composition of PN-rGO, we carried out XPS measurement. As shown in Figure 4a, the XPS survey spectrum of PN-rGO presented a dominant $\mathrm{C} 1 \mathrm{~s}$ peak $(\sim 284.5 \mathrm{eV})$, a O1s peak $(\sim 532.0 \mathrm{eV})$, a P2p peak $(\sim 132.8 \mathrm{eV})$, and a N1s peak $(\sim 400.0 \mathrm{eV})$, confirming successful $\mathrm{P}$ and $\mathrm{N}$ co-doping [28]; the corresponding atomic percentages were 92.47, 6.02, 1.16 , and 0.35 at. $\%$, respectively.

High-resolution spectra were then obtained to gain more insight into the phosphorus and nitrogen doping.

As shown in Figure 4b, the high-resolution P2p spectrum can be deconvoluted into two main component peaks located at 131.7 and $133.1 \mathrm{eV}$, corresponding to $\mathrm{P}-\mathrm{C}$ and $\mathrm{P}-\mathrm{O}$ bonding, respectively [23]. In addition, the peak area ratio of $\mathrm{P}-\mathrm{C}$ to $\mathrm{P}-\mathrm{O}$ is close to 2:3. Doping phosphorus atoms into the carbon lattice (forming a $\mathrm{P}-\mathrm{C}$ covalent bond) can induce negatively delocalized $\mathrm{C}$ atoms adjacent to $\mathrm{P}$ atoms; meanwhile, in $\mathrm{P}-\mathrm{O}$ bonding (where an oxygen bridge is formed between $\mathrm{C}$ and $\mathrm{P}$ ), the oxygen atoms can enhance electron poverty in the carbon atoms. These two kinds of structure have been reported to be advantageous for the ORR [29]. It should be pointed out that, there 
is always the debate if $\mathrm{P}$ can access to the honeycomb crystal lattice of graphene like what $\mathrm{N}$ or $\mathrm{B}$ atom does, due to the big difference of carbon and phosphorous in radius [30].

The deconvolution results of the high-resolution N1s spectrum were shown in Figure 4c. It's shown the prepared PN-rGO catalyst had four types of $\mathrm{N}$ species, corresponding to oxidized $\mathrm{N}(\sim 403.3 \mathrm{eV})$, graphitic $\mathrm{N}(\sim 401.4 \mathrm{eV})$, pyrrolic $\mathrm{N}(\sim 399.6 \mathrm{eV})$, and pyridinic $\mathrm{N}(\sim 398.3 \mathrm{eV})[31,32]$, with compositions of $31.0,32.3,20.8$, and 15.9 at. \%, respectively [33]. The total amount of active $\mathrm{N}$ species (graphitic N, pyrrolic N, and pyridinic $\mathrm{N}$ ) reached 69.0 at. \% [34].
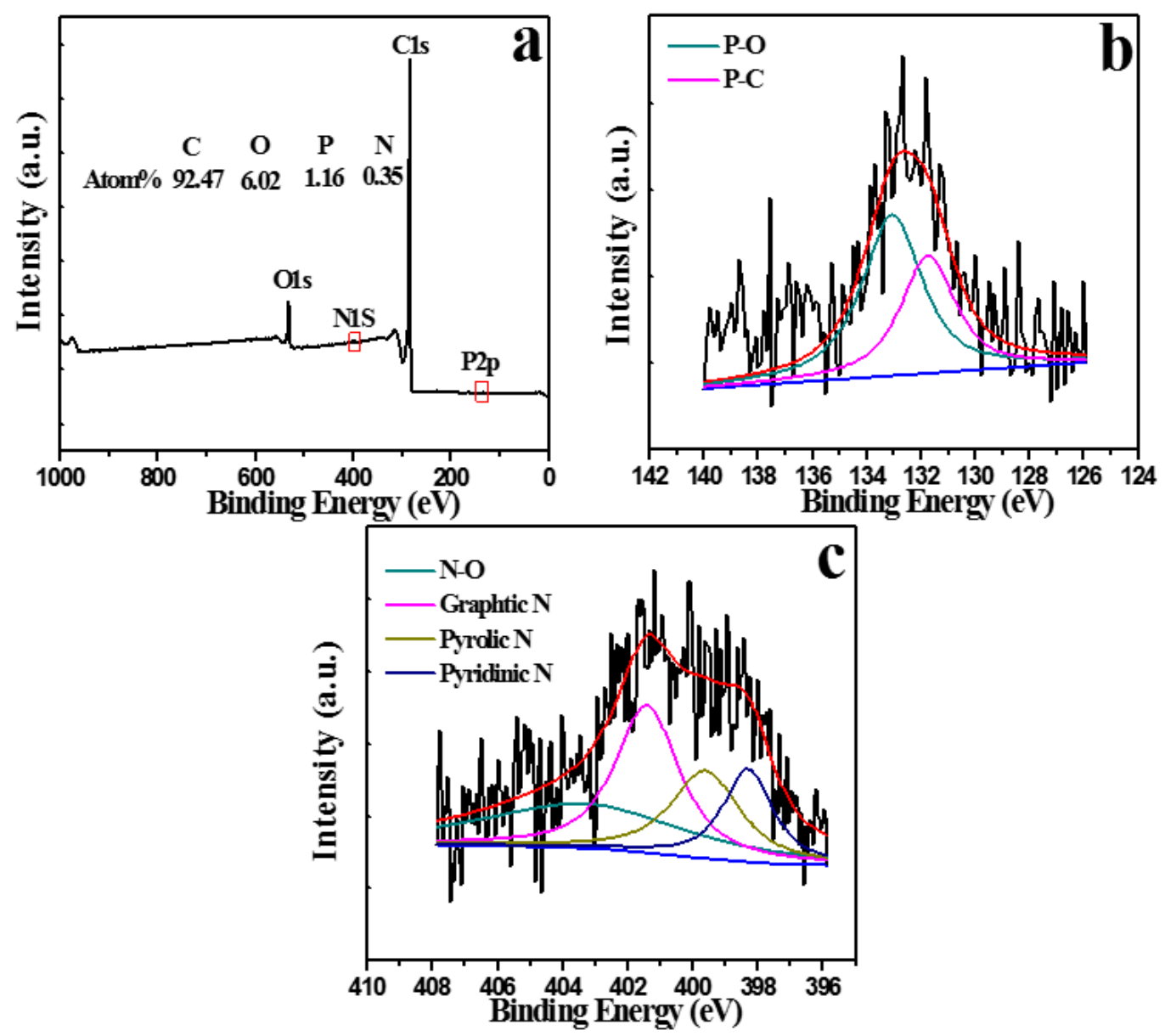

Figure 4. X-ray photoelectron spectroscopy (XPS) survey (a) and high resolution P2p (b), and N1s (c) spectra of PN-rGO.

To explore the electrocatalytic activity of PN-rGO for the ORR, cyclic voltammetry (CV) experiments were carried out in an $\mathrm{O}_{2}$-saturated $0.1 \mathrm{M} \mathrm{KOH}$ solution. The $\mathrm{CV}$ curves of a bare GCE and rGO were also measured for comparison. As shown in Figure 5a, for all the electrodes, the CV curves displayed distinct oxygen reduction cathodic peaks. The ORR peak potential positively shifted from $-0.39 \mathrm{~V}$ for the GCE to $-0.26 \mathrm{~V}$ for $\mathrm{rGO}$ and $-0.21 \mathrm{~V}$ for PN-rGO. In addition, the PN-rGO had the highest peak current density, at $-0.96 \mathrm{~mA} \mathrm{~cm}^{-2}$, which was about four times higher than that of the GCE. The most positive ORR peak potential and the highest peak current density of PN-rGO, suggest that phosphorus and trace nitrogen co-doping can greatly enhance the ORR catalytic activity of graphene. The $\mathrm{CV}$ area of the $\mathrm{PN}-\mathrm{rGO}$ was also much greater than that of the rGO, indicating the former had a much greater electroactive area, as CV area is closely related to a sample's 
capacitance, which is proportional to its specific surface area. This result is in good agreement with the BET results.

To gain further insight into the role of $\mathrm{P}, \mathrm{N}$ co-doping in the ORR, the linear sweep voltammetry (LSV) curve of PN-rGO was recorded in an $\mathrm{O}_{2}$-saturated $0.1 \mathrm{M} \mathrm{KOH}$ solution; for comparison, analogous LSV curves were also obtained for GCE, rGO, and commercial $20 \mathrm{wt}$ \% $\mathrm{Pt} / \mathrm{C}$. As can be seen in Figure 5b, PN-rGO had a much more positive ORR onset potential and a much higher limiting current density than GCE or rGO, indicating that doping graphene with phosphorus and trace nitrogen can facilitate the ORR. The LSV results are consistent with the CV results.
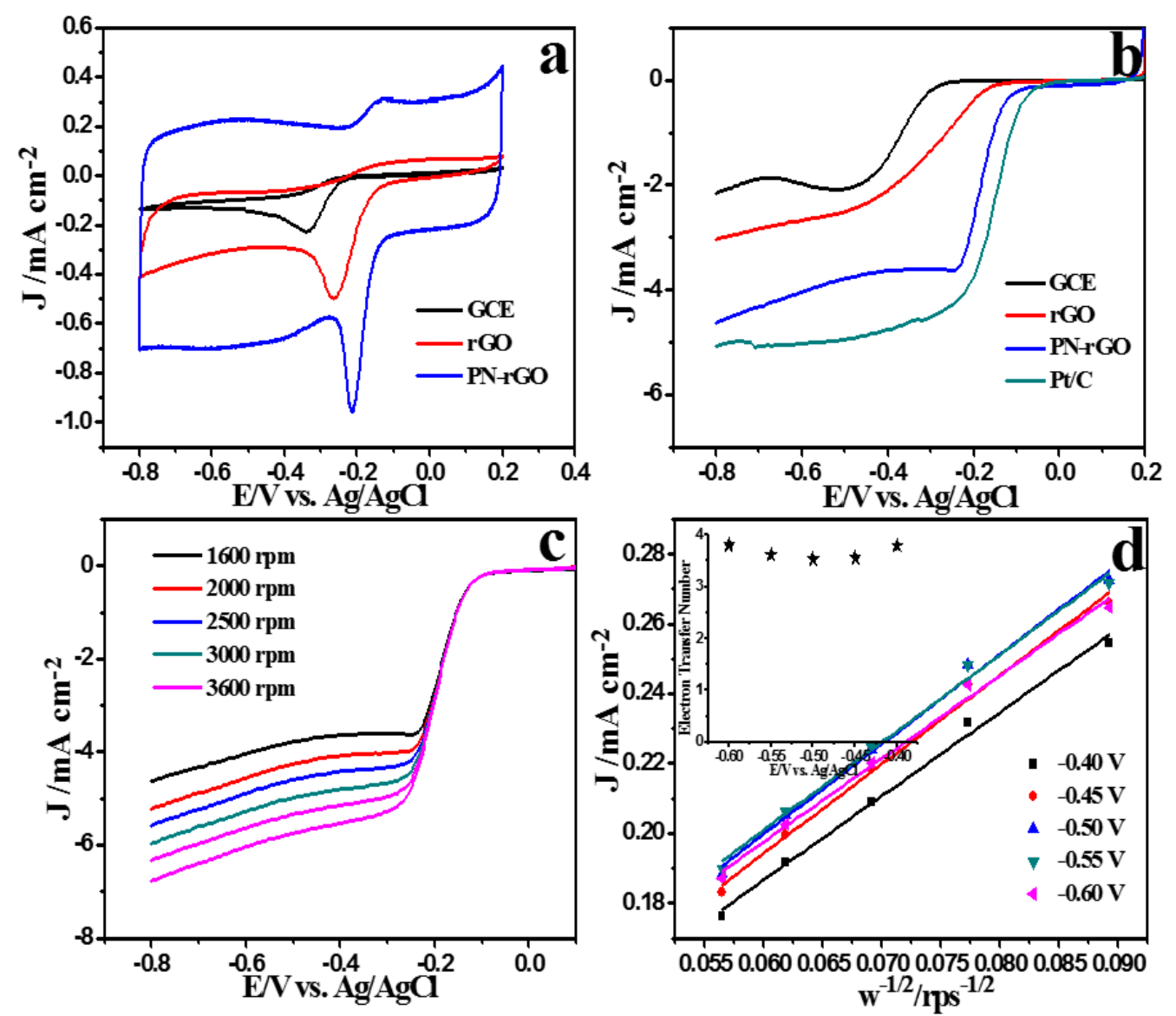

Figure 5. Cyclic voltammetry (CV) curves (a) and linear sweep voltammetry (LSV) curves at $1600 \mathrm{rpm}$ (b) for different samples, LSV curves at different rotation rates (c) and the corresponding K-L plots (d) of PN-rGO.

To gain more information on the ORR kinetics of the PN-rGO catalyst, we recorded LSV curves in an $\mathrm{O}_{2}$-saturated $0.1 \mathrm{M} \mathrm{KOH}$ solution at various rotation rates, from 1600 to $3600 \mathrm{rpm}$ (Figure 5c). The diffusion current density increased rapidly as the rotation rate increased. In addition, the K-L plots at different electrode potentials displayed good linearity, We used the K-L equation to calculate the electron transfer number (n) of PN-rGO in the potential range of -0.40 to $-0.60 \mathrm{~V}$ and obtained an average $n$ value of 3.66, indicating that the ORR proceeded via a dominated four-electron pathway.

For practical application in fuel cells, the fuel crossover effect should be considered because fuel molecules (e.g., methanol) may pass from anode to cathode through the membrane and poison the cathode catalyst. Thus, we recorded the chronoamperometric responses of $\mathrm{PN}-\mathrm{rGO}$ and $\mathrm{Pt} / \mathrm{C}$ upon 
the addition of $3 \mathrm{M}$ methanol (Figure 6a). After the methanol was introduced into an $\mathrm{O}_{2}$-saturated $0.1 \mathrm{M} \mathrm{KOH}$ solution at about $200 \mathrm{~s}$, no noticeable change was observed in the ORR current for $\mathrm{PN}-\mathrm{rGO}$; in contrast, $\mathrm{Pt} / \mathrm{C}$ showed a significant drop in ORR current. These results indicated that PN-rGO possessed a high immunity to methanol crossover.

As durability is also of great importance in practical applications of fuel-cell technology, the chronoamperometric durabilities of PN-rGO and $\mathrm{Pt} / \mathrm{C}$ were measured at $-0.3 \mathrm{~V}$ for $20,000 \mathrm{~s}$ in an $\mathrm{O}_{2}$-saturated $0.1 \mathrm{M} \mathrm{KOH}$ solution. As can be seen in Figure $6 \mathrm{~b}$, slight performance attenuation with high current retention (96\%) was achieved with our PN-rGO catalyst. However, commercial Pt/C suffered a current loss of $12 \%$ under the same conditions, indicating that the PN-rGO electrocatalyst was much more stable in an alkaline medium.
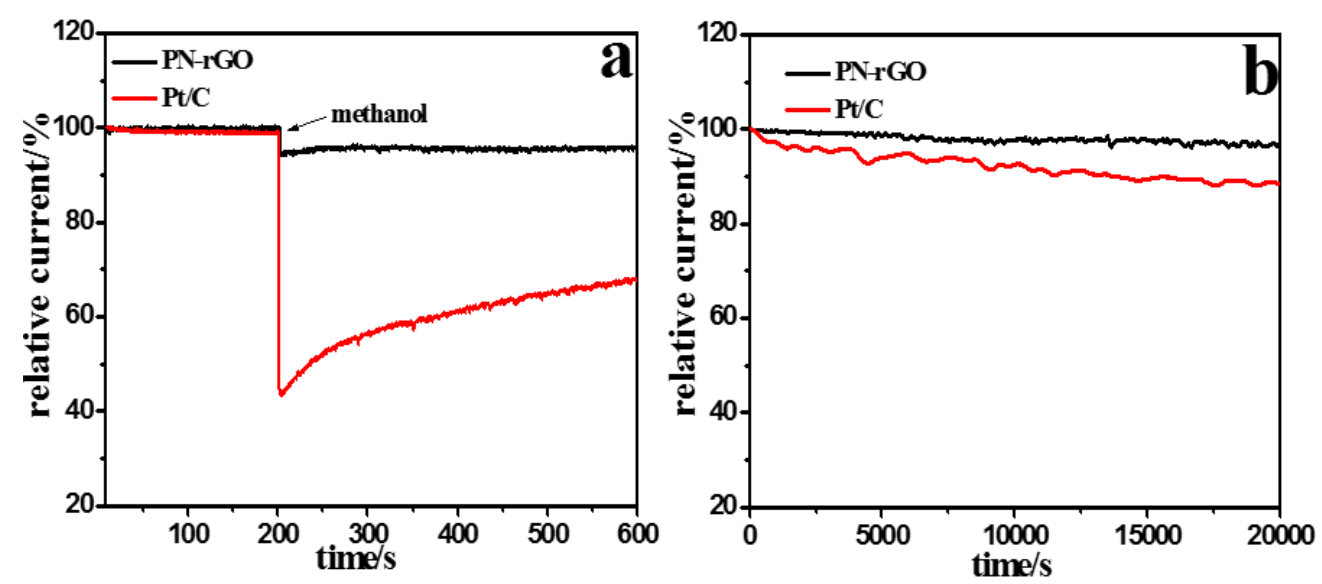

Figure 6. chronoamperometric responses of $\mathrm{PN}-\mathrm{rGO}$ and $\mathrm{Pt} / \mathrm{C}$ at $-0.3 \mathrm{~V}$ upon the addition of methanol (a), durability testing curves of PN-rGO and $\mathrm{Pt} / \mathrm{C}$ for $20,000 \mathrm{~s}$ at $1600 \mathrm{rpm}(\mathbf{b})$.

\section{Experimental Section}

\subsection{Catalysts Preparation}

Graphite oxide (GO) was prepared from 10,000 mesh graphite powder using a modified Hummers' Method. PN-rGO was synthesized by the thermal annealing of $\mathrm{GO}$ and $\left(\mathrm{NH}_{4}\right)_{2} \mathrm{HPO}_{4}$. In a typical procedure, $50 \mathrm{mg}$ of $\mathrm{GO}$ was mixed with $15 \mathrm{mg}$ of $\left(\mathrm{NH}_{4}\right)_{2} \mathrm{HPO}_{4}$ in $50 \mathrm{~mL}$ of deionized water, at room temperature, under stirring in an open beaker. After the water was completely removed using a rotary evaporator at $50{ }^{\circ} \mathrm{C}$, the resulting mixture was transferred into a quartz boat in the center of a tube furnace and annealed at $900{ }^{\circ} \mathrm{C}$ for $1 \mathrm{~h}$, with high-purity argon as the protective atmosphere. For comparison, reduced graphene oxide without $\mathrm{P}, \mathrm{N}$ doping ( $\mathrm{rGO}$ ) was also prepared using the same procedure but in the absence of $\left(\mathrm{NH}_{4}\right)_{2} \mathrm{HPO}_{4}$.

\subsection{Physical Characterization}

Scanning electron microscopy (SEM) was performed on a Nova Nano 430 field emission scanning electron microscope (FEI, Hillsboro, OR, USA). Transmission electron microscopy (TEM) images were recorded on JEM-2100HR transmission electron microscope (JEOL, Tokyo, Japan). X-ray 
diffraction (XRD) patterns were conducted on a TD-3500 powder diffractometer (Tongda, Liaoning, China). Raman spectroscopy measurements were carried out on a Lab RAM Aramis Raman spectrometer (HORIBA Jobin Yvon, Edison, NJ, USA) with a laser wave length of $632.8 \mathrm{~nm}$. Surface area and pore characteristics were determined by recording nitrogen adsorption-desorption isotherms using a Tristar II 3020 gas adsorption analyzer (Micromeritics, Norcross, GA, USA). X-ray photoelectron spectroscopy (XPS) was performed with an ESCALAB 250 X-ray photoelectron spectrometer (Thermo-VG Scientific, Waltham, MA, USA).

\subsection{Electrochemical Measurements}

Electrochemical measurements were carried out on an electrochemical workstation (Ivium, Eindhoven, The Netherlands) with a standard three-electrode system at room temperature. A glassy carbon rotating disk electrode (GC-RDE) $\left(5 \mathrm{~mm}\right.$ diameter, $0.196 \mathrm{~cm}^{2}$ geometric area) was used as the working electrode, while a $\mathrm{Pt}$ wire and an $\mathrm{Ag} / \mathrm{AgCl}(3 \mathrm{M} \mathrm{NaCl})$ electrode were the counter and reference electrodes, respectively. The electrolyte was $0.1 \mathrm{M}$ aqueous $\mathrm{KOH}$ solution. For each sample, a catalyst ink was prepared by dispersing $5 \mathrm{mg}$ of the corresponding catalyst in $1 \mathrm{~mL}$ Nafion ethanol solution $(0.25 \cdot$ wt. \%). Then $20 \mu \mathrm{L}$ of the dispersed catalyst ink was pipetted onto the GC-RDE and dried under an infrared lamp. The mass loading of the catalyst was $0.5 \mathrm{mg} \cdot \mathrm{cm}^{-2}$. Before testing, the electrolyte solution was purged with high-purity nitrogen or oxygen gas for at least $30 \mathrm{~min}$. Unless otherwise specified, the scanning rate was $10 \mathrm{mV} \cdot \mathrm{s}^{-1}$. The electron transfer number $(n)$ per oxygen molecule involved was calculated on the basis of the Koutecky-Levich (K-L) equation:

$$
\begin{aligned}
& J^{-1}=J_{\mathrm{L}}^{-1}+J_{\mathrm{K}}{ }^{-1}=B^{-1} \omega^{-1 / 2}+J_{\mathrm{K}}{ }^{-1} \\
& B=0.62 n F C_{0} D_{0}^{2 / 3} \gamma^{-1 / 6} \\
& J_{\mathrm{K}}=n F \kappa C_{0}
\end{aligned}
$$

where $J$ is the measured current density; $J_{\mathrm{K}}$ and $J_{\mathrm{L}}$ are the kinetic current density and the diffusion limiting current density, respectively; $\omega$ is the angular velocity of the disk $(\omega=2 \pi N$, where $N$ is the linear rotation rate); $n$ is the number of electrons transferred for the ORR; $F$ is the Faraday constant $\left(F=96485 \mathrm{C} \cdot \mathrm{mol}^{-1}\right) ; C_{0}$ is the bulk concentration of $\mathrm{O}_{2}\left(1.2 \times 10^{-3} \mathrm{~mol} \cdot \mathrm{L}^{-1}\right) ; D_{0}$ is the diffusion coefficient of $\mathrm{O}_{2}$ in $0.1 \mathrm{M} \mathrm{KOH}\left(1.9 \times 10^{-5} \mathrm{~cm}^{2} \cdot \mathrm{s}^{-1}\right) ; \gamma$ is the kinetic viscosity of the electrolyte $\left(0.01 \mathrm{~cm}^{2} \cdot \mathrm{s}^{-1}\right)$; and $\kappa$ is the electron transfer rate constant.

\section{Conclusions}

A metal-free phosphorus and nitrogen dual-doped reduced graphene oxide (PN-rGO) catalyst was successfully synthesized using a one-step thermal annealing method by directly pyrolyzing a homogenous mixture of graphite oxide $(\mathrm{GO})$ and diammonium hydrogen phosphate $\left(\left(\mathrm{NH}_{4}\right)_{2} \mathrm{HPO}_{4}\right)$. The specific surface area of PN-rGO, $376.2 \mathrm{~m}^{2} \cdot \mathrm{g}^{-1}$, was much higher than that of $\mathrm{rGO}\left(260.2 \mathrm{~m}^{2} \cdot \mathrm{g}^{-1}\right)$. The catalyst exhibited enhanced ORR activity via a dominant four-electron reduction pathway and showed outstanding selectivity and stability in an alkaline solution. Certainly, the details of the ORR mechanism and active sites of this new catalyst require further investigation. 


\section{Acknowledgments}

The authors would like to acknowledge the financial support of the National Science Foundation of China (NSFC Project No. 21076089, 21276098, 11132004, and U1301245), the Ministry of Science and Technology of China (Project No. 2012AA053402), the Guangdong Natural Science Foundation (Project No. S2012020011061), the Doctoral Fund of the Ministry of Education of China (20110172110012), and the Basic Scientific Foundation of the Central Universities of China (No. 2013ZP0013).

\section{Author Contributions}

X. Q. performed the expermient and analyzed the date; X. Q. and S. L. wrote the paper; C. Y. and R. C analyzed the date.

\section{Conflicts of Interest}

The authors declare no conflict of interest.

\section{References}

1. Debe, M.K. Electrocatalyst approaches and challenges for automotive fuel cells. Nature 2012, 486, 43-51.

2. Winter, M.; Brodd, R.J. What are batteries, fuel cells, and supercapacitors? Chem Rev. 2004, 104, 4245-4270.

3. Lefèvre, M.; Proietti, E.; Jaouen, F.; Dodelet, J.-P. Iron-based catalysts with improved oxygen reduction activity in polymer electrolyte fuel cells. Science 2009, 324, 71-74.

4. Wu, G.; More, K.L.; Xu, P.; Wang, H.L.; Ferrandon, M.; Kropf, A.J.; Myers, D.J.; Ma, S.; Johnston, C.M.; Zelenay, P. A carbon-nanotube-supported graphene-rich non-precious metal oxygen reduction catalyst with enhanced performance durability. Chem. Commun. 2013, 49, 3291-3293.

5. Liang, Y.; Wang, H.; Diao, P.; Chang, W.; Hong, G.; Li, Y.; Gong, M.; Xie, L.; Zhou, J.; Wang, J.; et al. Oxygen reduction electrocatalyst based on strongly coupled cobalt oxide nanocrystals and carbon nanotubes. J. Am. Chem. Soc. 2012, 134, 15849-15857.

6. Duan, J.; Zheng, Y.; Chen, S.; Tang, Y.; Jaroniec, M.; Qiao, S. Mesoporous hybrid material composed of $\mathrm{Mn}_{3} \mathrm{O}_{4}$ nanoparticles on nitrogen-doped graphene for highly efficient oxygen reduction reaction. Chem. Commun. 2013, 49, 7705-7707.

7. Andersen, N.I.; Serov, A.; Atanassov, P. Metal oxides/CNT nano-composite catalysts for oxygen reduction/oxygen evolution in alkaline media. Appl. Catal. B 2015, 163, 623-627.

8. Qiao, X.; You, C.; Shu, T.; Fu, Z.; Zheng, R.; Zeng, X.; Li, X.; Liao, S. A one-pot method to synthesize high performance multielement co-doped reduced graphene oxide catalysts for oxygen reduction. Electrochem. Commun. 2014, 47, 49-53.

9. Holade, Y.; Sahin, N.E.; Servat, K.; Napporn, T.W.; Kokoh, K.B. Recent advances in carbon supported metal nanoparticles preparation for oxygen reduction reaction in low temperature fuel cells. Catalysts 2015, 5, 310-348. 
10. Niu, W.; Li, L.; Liu, X.; Wang, N.; Liu, J.; Zhou, W.; Tang, Z.; Chen, S. Mesoporous N-doped carbons prepared with thermally removable nanoparticle templates: An efficient electrocatalyst for oxygen reduction reaction. J. Am. Chem. Soc. 2015, 137, 5555-5562.

11. Xia, W.; Masa, J.; Bron, M.; Schuhmann, W.; Muhler, M. Highly active metal-free nitrogen-containing carbon catalysts for oxygen reduction synthesized by thermal treatment of polypyridine-carbon black mixtures. Electrochem. Commun. 2011, 13, 593-596.

12. Gong, K.; Du, F.; Xia, Z.; Durstock, M.; Dai, L. Nitrogen-doped carbon nanotube arrays with high electrocatalytic activity for oxygen reduction. Science 2009, 323, 760-764.

13. Yang, Z.; Yao, Z.; Li, G.; Fang, G.; Nie, H.; Liu, Z.; Zhou, X.; Chen, X.A.; Huang, S. Sulfur-doped graphene as an efficient metal-free cathode catalyst for oxygen reduction. ACS Nano 2011, 6, 205-211.

14. Bo, X.; Guo, L. Ordered mesoporous boron-doped carbons as metal-free electrocatalysts for the oxygen reduction reaction in alkaline solution. Phys. Chem. Chem. Phys. 2013, 15, 2459-2465.

15. Lherbier, A.; Blase, X.; Niquet, Y.-M.; Triozon, F.; Roche, S. Charge transport in chemically doped 2D graphene. Phys. Rev. Lett. 2008, 101, 036808.

16. Liu, H.; Liu, Y.; Zhu, D. Chemical doping of graphene. J. Mater. Chem. 2011, 21, 3335-3345.

17. Zhou, X.; Qiao, J.; Yang, L.; Zhang, J. A review of graphene-based nanostructural materials for both catalyst supports and metal-free catalysts in PEM fuel cell oxygen reduction reactions. $A d v$. Energy Mater. 2014, 4, doi:10.1002/aenm.201301523.

18. Sheng, Z.-H.; Gao, H.-L.; Bao, W.-J.; Wang, F.-B.; Xia, X.-H. Synthesis of boron doped graphene for oxygen reduction reaction in fuel cells. J. Mater. Chem. 2012, 22, 390-395.

19. Qu, L.; Liu, Y.; Baek, J.-B.; Dai, L. Nitrogen-doped graphene as efficient metal-free electrocatalyst for oxygen reduction in fuel cells. ACS Nano 2010, 4, 1321-1326.

20. Yao, Z.; Nie, H.; Yang, Z.; Zhou, X.; Liu, Z.; Huang, S. Catalyst-free synthesis of iodine-doped graphene via a facile thermal annealing process and its use for electrocatalytic oxygen reduction in an alkaline medium. Chem. Commun. 2012, 48, 1027-1029.

21. Sfaelou, S.; Zhuang, X.; Feng, X.; Lianos, P. Sulfur-doped porous carbon nanosheets as high performance electrocatalysts for photofuelcells. RSC Adv. 2015, 5, 27953-27963.

22. Geng, D.; Chen, Y.; Chen, Y.; Li, Y.; Li, R.; Sun, X.; Ye, S.; Knights, S. High oxygen-reduction activity and durability of nitrogen-doped graphene. Energy Environ. Sci. 2011, 4, 760-764.

23. Li, R.; Wei, Z.; Gou, X.; Xu, W. Phosphorus-doped graphene nanosheets as efficient metal-free oxygen reduction electrocatalysts. RSC Adv. 2013, 3, 9978.

24. Zhang, C.; Mahmood, N.; Yin, H.; Liu, F.; Hou, Y. Synthesis of phosphorus-doped graphene and its multifunctional applications for oxygen reduction reaction and lithium ion batteries. Adv. Mater. 2013, 25, 4932-4937.

25. Choi, C.H.; Chung, M.W.; Kwon, H.C.; Park, S.H.; Woo, S.I. B, N-and P, N-doped graphene as highly active catalysts for oxygen reduction reactions in acidic media. J. Mater. Chem. A 2013, 1, 3694-3699.

26. Kyotani, T. Control of pore structure in carbon. Carbon 2000, 38, 269-286. 
27. Sun, J.; Wu, L.; Wang, Q. Comparison about the structure and properties of pan-based activated carbon hollow fibers pretreated with different compounds containing phosphorus. J. Appl. Polym. Sci. 2005, 96, 294-300.

28. Liu, Z.W.; Peng, F.; Wang, H.J.; Yu, H.; Zheng, W.X.; Yang, J. Phosphorus-doped graphite layers with high electrocatalytic activity for the $\mathrm{O}_{2}$ reduction in an alkaline medium. Angew. Chem. 2011, 123, 3315-3319.

29. Choi, C.H.; Park, S.H.; Woo, S.I. Binary and ternary doping of nitrogen, boron, and phosphorus into carbon for enhancing electrochemical oxygen reduction activity. ACS Nano 2012, 6, 7084-7091.

30. Geng, D.; Ding, N.; Hor, T.S.A.; Liu, Z.; Sun, X.; Zong, Y. Potential of metal-free "graphene alloy" as electrocatalysts for oxygen reduction reaction. J. Mater. Chem. A 2015, 3, 1795-1810.

31. Wohlgemuth, S.-A.; White, R.J.; Willinger, M.-G.; Titirici, M.-M.; Antonietti, M. A one-pot hydrothermal synthesis of sulfur and nitrogen doped carbon aerogels with enhanced electrocatalytic activity in the oxygen reduction reaction. Green Chem. 2012, 14, 1515-1523.

32. Nagaiah, T.C.; Kundu, S.; Bron, M.; Muhler, M.; Schuhmann, W. Nitrogen-doped carbon nanotubes as a cathode catalyst for the oxygen reduction reaction in alkaline medium. Electrochem. Commun. 2010, 12, 338-341.

33. Vikkisk, M.; Kruusenberg, I.; Joost, U.; Shulga, E.; Kink, I.; Tammeveski, K. Electrocatalytic oxygen reduction on nitrogen-doped graphene in alkaline media. Appl. Catal. B 2014, 147, 369-376.

34. Qiao, X.; Peng, H.; You, C.; Liu, F.; Zheng, R.; Xu, D.; Li, X.; Liao, S. Nitrogen, phosphorus and iron doped carbon nanospheres with high surface area and hierarchical porous structure for oxygen reduction. J. Power Sources 2015, 288, 253-260.

(C) 2015 by the authors; licensee MDPI, Basel, Switzerland. This article is an open access article distributed under the terms and conditions of the Creative Commons Attribution license (http://creativecommons.org/licenses/by/4.0/). 